\title{
Indigo formation and rapid NADPH consumption provide robust prediction of raspberry ketone synthesis by engineered cytochrome P450 BM3.
}

\author{
Olivier Rousseau ${ }^{[a, b, d]}$, Maximilian C.C.J.C. Ebert ${ }^{[b, c, d]}$, Daniela Quaglia ${ }^{[a, b, d]}$, Ali Fendri ${ }^{[a, b, d]}$, Adem H.- \\ Parisien ${ }^{[b, c, d]}$, Jonathan N. Besna ${ }^{[b, c, d]}$,Saathanan Iyathurai ${ }^{[b, c, d]}$ and Joelle N. Pelletier ${ }^{[a, b, c, d]}{ }^{*}$
}

\begin{abstract}
Natural raspberry ketone has a high value in the flavor, fragrance and pharmaceutical industries. Its extraction is costly, justifying the search for biosynthetic routes. We hypothesized that cytochrome P450 BM3 (P450 BM3) could be engineered to catalyze the hydroxylation of 4phenyl-2-butanone, a naturally sourceable precursor, to raspberry ketone. The synthesis of indigo by variants of P450 BM3 has previously served as a predictor of promiscuous oxidation reactions. To this end, we screened 53 active-site variants of P450 BM3 using orthogonal high-throughput workflows to identify the most streamlined route to all indigo-forming variants. Among the three known and 13 new indigo-forming variants, eight hydroxylated 4-phenyl-2-butanone
\end{abstract}

\section{Introduction}

Substituted phenols are highly sought-after industrial intermediates and products. ${ }^{[1]}$ Among these, 4-(4-hydroxyphenyl)2-butanone, also known as rheosmin or raspberry ketone, is of high value for the flavor and fragrance industry and is under investigation for its potential health benefits. ${ }^{[2]}$ The cost of extracting natural raspberry ketone from raspberries and other fruits $(20000 \$ / \mathrm{kg})$ justifies the development of synthetic and biosynthetic routes to access this small molecule. ${ }^{[3]}$ In particular, biocatalytic routes can be applied to transform natural precursors into products then considered to be 'natural', offering regulatory advantages for applications in the food and fragrance markets. ${ }^{[3 \mathrm{e}]}$

Cytochrome P450 oxidases constitute a superfamily of $\mathrm{NAD}(\mathrm{P}) \mathrm{H}$-dependent mono-oxygenases that catalyze reactions on a wide range of substrates, ${ }^{[4]}$ including the degradation of xenobiotics and endogenous molecules. ${ }^{[5]}$ They catalyze hydroxylation, epoxidation, deamination, dehalogenation, dealkylation and more, acting on non-activated carbon atoms in a single step. The breadth of their reactivity gives them great industrial importance ${ }^{[6]}$ Cytochrome P450 oxidase BM3 (P450 $\mathrm{BM} 3$ ), from Bacillus megaterium, is a self-sufficient cytochrome $\mathrm{P} 450$. Its reductase domain is fused to its heme domain, making it among the most efficient cytochrome P450 oxidases with respect to electron transfer. Although the primary physiological function of P450 BM3 remains unclear, fatty acids are its native substrates. The native P450 BM3 and, to a greater extent, its engineered variants, oxidize substrates as chemically diverse as methane, numerous terpenes and alkaloids, heteroaromatics and many natural and non-natural, bulkier molecules such as buspirone and dextromethorphan, $\left.{ }^{[6 a}, 7\right]$ making P450 BM3 a versatile enzyme that offers good promiscuity for substrate discovery.

Screening assays to explore the versatility of cytochrome $\mathrm{P} 450$ s have been developed, particularly assays that rely on chromogenic or derivatized substrates and products. ${ }^{[8]}$ Monitoring cytochrome P450 oxidase variants for the oxidation of indole to indoxyl is particularly attractive because indoxyl undergoes spontaneous oxidative dimerization to the readily-detectable deep blue pigment indigo (Figure 1A). Chromogenic reactions address one of the main bottlenecks of high-throughput screening: reactivity can be detected in whole cells or in cell lysate, reducing

[a] Department of Chemistry, Université de Montréal

[b] Center for Green Chemistry and Catalysis (CGCC), Université de Montréal

[c] Department of Biochemistry, Université de Montréal 2900 Édouard-Montpetit, Montréal, Québec, H3T 1J4, Canada

[d] PROTEO, The Québec Network for Research on Protein Function Engineering and Applications, Québec, QC, Canada G1V OA6

* Corresponding author: joelle.pelletier@umontreal.ca to raspberry ketone. Previously unreported variant $A 82 \mathrm{Q}$ displayed the highest initial rates and coupling efficiencies in synthesis of indigo and of raspberry ketone. It produced the highest total concentration of raspberry ketone despite producing less total indigo than previously reported variants. Its productivity, although modest, clearly demonstrates the potential for development of a biocatalytic route to raspberry ketone. In addition to validating indigo as a robust predictor of this promiscuous activity, we demonstrate that monitoring rapid NADPH consumption serves as an alternative predictor of a promiscuous reactivity in P450 BM3.

time and cost of screening as only well-expressed, active and soluble variants are identified in a high-throughput format.

We hypothesized that P450 BM3 could be a potential candidate enzyme for the oxidative biotransformation of 4-phenyl2-butanone (4-PB) to raspberry ketone (Figure 1B). The substrate, $4-\mathrm{PB}$, is a major fraction of the essential oils of the tropical Aquilaria trees and thus can be naturally sourced. ${ }^{\left[{ }^{[0]}\right.}$ Neither substrate nor product of the reaction are obvious candidates for visual library screening. It has been demonstrated that screening cytochrome P450 variants for improved oxidative activity toward indigo formation can be a successful route to identifying variants that are promiscuously active. Substrates identified by that method include branched fatty acids, pentane, dioxins, cyclic terpenoids, coumarins and substituted aromatics, and polyaromatics such as toluene, indoles and quinolones. ${ }^{[10]}$ Even modest levels of indigo synthesis have proven to be of value as a start-point for evolution toward broader substrate promiscuity and improved activity. ${ }^{[10 f, 11]}$

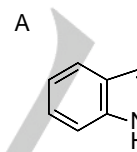

Indole B

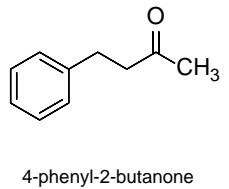
$(4-\mathrm{PB})$

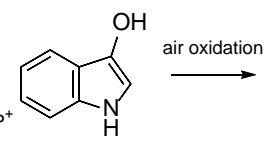

Indoxyl

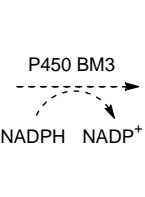

Figure 1. Role of cytochrome P450 BM3 in (A) the biotransformation of indole to indigo and (B) the proposed biotransformation of 4-phenyl-2-butanone (4-PB) to raspberry ketone.

One study of P450 CAM variants found a 96\% correlation between the hydroxylation of indole and an unrelated substrate, diphenylmethane..$^{[10 b]}$ Here, we set out to verify the efficacy of indole oxidation in the microbial, self-sufficient P450 BM3 as a predictor of promiscuous activity for the unrelated substrate, 4-PB. Specifically, we considered it important to determine whether, independently of indigo production, all well-folded and functional BM3 variants are equally good candidates for this promiscuous activity. We verified whether variants exhibiting the highest indole oxidation to indigo correlated with the highest 4-PB oxidation. We also verified whether high NADPH consumption may be indicative of a greater propensity to oxidize 4-PB. We compare experimental outputs to determine the most efficient workflow to identify novel P450 BM3 variants that hydroxylate 4-PB to raspberry ketone. 


\section{Results and Discussion}

Indigo is among the oldest dyes and finds utility in diverse industries such as textiles, food, and pharmaceuticals. ${ }^{[12]}$ Synthetic biology and biocatalytic solutions to indigo production have been sought in the past. ${ }^{[10 \mathrm{~b}, 13]}$ Among these, engineered variants of P450 BM3 have been found to be active toward the oxidation of indole to indoxyl, and thence to indigo. ${ }^{[\mathrm{aa}, 7 \mathrm{c}]} \mathrm{We}$ sought to exploit the correlation that has been observed between that oxidative transformation and the oxidation of other non-native substrates in some cytochrome P450s to identify variants active in the production of raspberry ketone.

The chemical space of P450 BM3 has been only lightly tapped into with respect to indigo-producing variants. With the aim of identifying new indigo-forming variants and broadening the search space for potential raspberry ketone production, we mutated and screened five active-site residues: V78, A82, F87, A264 and T268 (Figure 2). These positions were rationally selected based on distance from the heme-iron and side-chain orientation, and in some cases prior observation of indigo formation, as described below.

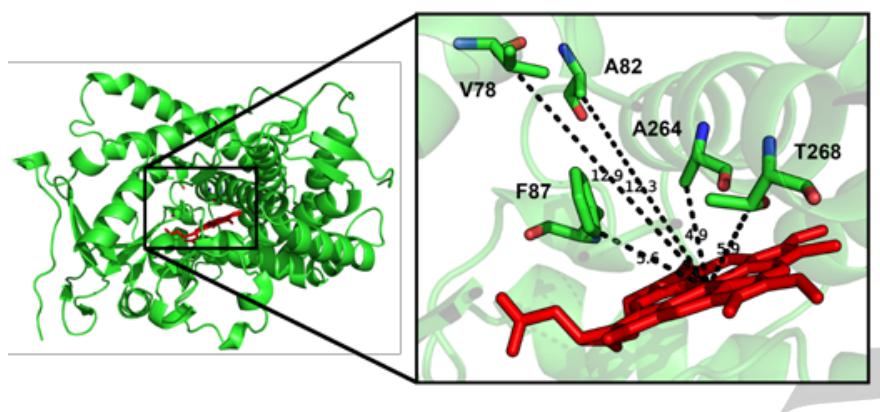

Figure 2. The five active-site positions selected for mutagenesis in $\mathrm{P} 450 \mathrm{BM}$ : V78, A82, F87, A264 and T268 in a close-up of the active-site (PDB code 1BU7) P450 BM3 is represented in green cartoon form and the heme in red sticks. Distances from the heme iron are shown $(\AA)$.

Several variants at positions A82 and F87 have been well characterized in the oxidation of natural substrates, drugs and metabolites. ${ }^{[7 c, 14]}$ Some are also known to catalyze indigo formation and to significantly modify the active site geometry; those two positions were further diversified. $\left.{ }^{[7 a}, 11 a, 15\right]$ Some variants at position V78 oxidize small substrates, a feature that is compatible with our goal, justifying its inclusion. ${ }^{16]}$ Specific substitutions at position A264 displace the heme iron-coordinating water molecule, and others at the highly conserved T268 alter its role in the oxidation mechanism, demonstrating the impact of these core active-site positions on reactivity. ${ }^{[17]}$ They were considered to be promising targets for modification. Sitesaturation mutagenesis was performed at these five positions using a mix of degenerate primers (Table S1). ${ }^{[18]}$ We obtained a coverage of $50-70 \%$ at each position, yielding a dataset of 53 variants (Table 1 ).

Table 1. $P 450 \mathrm{BM} 3$ variants screened in this study.

\begin{tabular}{|c|l|c|}
\hline Native residue & \multicolumn{1}{|c|}{ Variants screened } & $\begin{array}{c}\text { Coverage } \\
(/ 19)\end{array}$ \\
\hline V78 & A, D, F, G, K, N, S, W, Y & 9 \\
A82 & C, E, F, G, I, K, L, P, Q, R, T, V, W & 13 \\
F87 & A, H, I, K, L, N, P, Q , S , V, W & 11 \\
A264 & C, D, F, G, N, P, R, T, V & 9 \\
T268 & A, D, E, G, K, M, N, P, S, W, Y & 11 \\
\hline
\end{tabular}

Direct visual identification of indigo-forming bacterial colonies can be done upon plating on indole-containing medium $^{[11 a]}$. Though rapid, that method provides no quantification.
In our search for indigo-producing variants, we directly assayed clarified cell lysate for indigo formation using a microtiter-well format to monitor absorbance at $620 \mathrm{~nm}$ after $2 \mathrm{~h}$ of reaction. This allows ample time for the primary oxidation product, indoxyl, to spontaneously dimerize into indigo. ${ }^{[19]}$ Despite the poor water solubility of indigo, this method is sufficient to rank promising candidates. Direct absorbance in clarified lysate identified 14/53 variants producing indigo (Figure S1). These include three known indigo-forming variants, $\mathrm{A} 82 \mathrm{~F}, \mathrm{~A} 82 \mathrm{~W}$ and $\left.\mathrm{F} 87 \mathrm{~V},{ }^{[7 a}, 11 \mathrm{1}, 15\right]$ and we identified 11 unreported variants. Among these, substitutions at A82 and F87 displayed the highest activity; substitutions V78 and A264 also yielded positive hits. Only position T268 yielded no indigo-forming variants according to absorbance at $620 \mathrm{~nm}$. We note that, although it produced detectable indigo, the concentration produced by the WT was below the limit of quantification in our method.

We considered that 14 indigo-forming variants out of 53 variants screened was quite successful. It has been demonstrated that indigo formation in P450 BM3 is useful in searching for novel transformations. ${ }^{[10]}$ However, it is not known if indigo formation is a robust predictor. Specifically, how efficient is indigo formation in predicting variants displaying a novel reactivity and, in counterpart, are all variants displaying a novel reactivity indigo producers? To this end, we established a high-throughput workflow to accelerate the discovery of highly active variants that are independent of the indigo predictor, with a focus on NADPH consumption. We quantified functional expression of the 53 variants and screened them for NADPH consumption, followed by product formation by mass spectrometry.

We identified the variants that are well folded, including the heme iron, according to carbon monoxide (CO) difference spectroscopy in a microtiter plate format. [8a] This rapid and reliable quantification of functional expression of each variant demonstrated that 31 out of the 53 variants were functionally expressed (Figure S2). As expected, this included all 14 indigopositive variants. Under our conditions, we observed moderate variation of expression, as illustrated by the standard deviation on eight replicates of the wild-type P450 BM3. We note that SDSPAGE analysis of protein expression in lysates identified all COtest positive variants as being highly expressed; two further variants were highly expressed but negative in CO-testing (A82R and $T 268 \mathrm{~K}$ ), presumably because they did not successfully incorporate heme and/or iron (data not shown). Finally, this assay revealed one false positive, $\mathrm{F} 87 \mathrm{~W}$, which was a weak producer in the $A b_{620}$ assay but was negative in the CO test and was not considered thereafter.

We then optimized a NADPH-consumption fluorescence assay by adapting it to automation. This previously reported $96-$ well plate assay can apply to any NADPH-consuming reaction, including non-colorigenic reactions. [20] Hits were defined as variants consuming NADPH faster in the presence than in the absence of exogenous substrate. The high-throughput workflow was validated toward the conversion of indole. We originally performed the reaction with $0.375 \mathrm{mM} \mathrm{NADPH}$ to observe initial rates. Under those conditions, the difference between presence/ absence of exogenous substrate did not allow the clear identification of indole-reactive variants (data not shown). We therefore designed an assay with $1.5 \mathrm{mM} \mathrm{NADPH}$ : initial rates are not directly observed due to saturation of the fluorescence detector but clear rate discrimination is observed upon complete consumption of NADPH (Figure S3). Under these conditions, the NADPH fluorescence assay unveiled 29/31 CO-positive variants where NADPH was consumed faster in the presence than in the absence of indole (Table S2)

This result is substantially greater than the $14 / 53$ indigo producers identified by $\mathrm{Abs}_{620}$. We observed that indole activated NADPH consumption: all the well-expressed variants consumed faster in presence of this exogenous substrate. The poorlyexpressed T268M and T268W variants do not exhibit this behaviour. NADPH consumption in the bacterial lysates can result from the activity of other NADPH-dependent enzymes, from 
activity of $\mathrm{P} 450 \mathrm{BM} 3$ with endogenous substrates such as fatty acids or as a result of uncoupling of P450 BM3 to form $\mathrm{H}_{2} \mathrm{O}_{2}$, superoxide anion and water. [7a, 21]. Moreover, uncoupling can be substrate dependent: the T268A variant of P450 BM3 is known to exhibit uncoupling in the presence of $\mathrm{C}_{16}$ but not $\mathrm{C}_{14}$ fatty acid substrate. ${ }^{[22]}$ The assay may therefore not be a direct reflection of product formation. We thus validated product formation by mass spectrometry for the indole-activated NADPH-consuming variants.

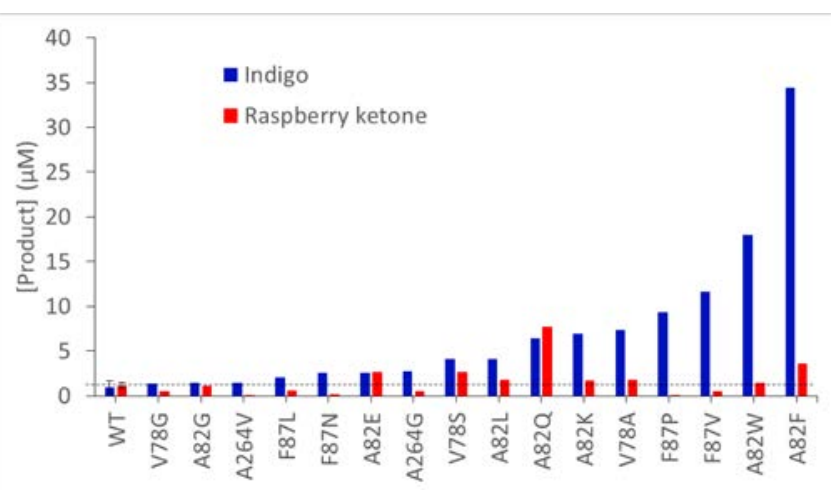

Figure 3. Quantification of indigo by LC-MS (blue) and raspberry ketone by GCMS (red) for the 16 best indigo producing variants of P450 BM3. Assays were performed in the presence of $5 \mathrm{mM}$ substrate and $1.5 \mathrm{mM}$ NADPH. The limit of quantification (lowest concentration in the linear portion of the calibration curve) for both products was $1.25 \mu \mathrm{M}$, indicated with a dashed line. Product concentration in WT is the average eight replicates with standard deviation.

Using LC-MS, we confirmed that 16 out of the $29 \mathrm{NADPH}$ fluorescence hits showed detectable levels of indigo (Figure 3; Table S2; Figure S4). The higher sensitivity of LC-MS led to the detection of two additional variants than the $\mathrm{Abs}_{620}$ assay: A264V and $A 82 G$, which were among the weakest indigo producers (Figure S5; Table S3). We defined variants as being indigo producers if they produced indigo $>2 \times$ the lowest concentration in the linear portion of the calibration curve $(1.25 \mu \mathrm{M})$ (Figure 4). We thus identified 12 indigo producers by LC-MS (Figure 4; Table S3). This demonstrates that the straightforward $A b_{620}$ assay identified all the best indigo producers, serving as a rapid and robust screen that is compatible with large libraries. Prolonging the $A_{b s_{620}}$ assay beyond $2 \mathrm{~h}$ did not reveal further indigo producers, but shortening the assay reduced its sensitivity. LCMS being more sensitive, it also identified weakly active variants. In certain contexts, these variants can also be good starting points to evolve the enzyme toward new functions.

Remarkably, more than half of the NADPH-consuming variants (16/29) gave indigo at concentrations $\geq 1.25 \mu \mathrm{M}$, demonstrating that active-site modification of P450 BM3 to oxidize indole is readily achievable. The previously reported variants $A 82 F, A 82 W$ and $F 87 V$ were among the most efficient indigo-producing variants. $\left.{ }^{[7,}, 23\right]$ Several of the best indigo producers are novel variants at those two positions (A82 and F87) such as F87P. It has been shown that aggressive substitution in P450 BM3, including substitution to proline, can be accommodated and result in unexpected and desirable outcomes. [21d] In addition, we report the first indigo-producing variants of position V78 and A264. Variant V78A ( $5^{\text {th }}$-best) was one of several mutations in variants reported to hydroxylate small alkanes ${ }^{[16 b]}$ or alter hydroxylation regiospecificity on $\mathrm{C}_{12}$ fatty acids. ${ }^{[24]}$ Variants of position A264 were weaker: A264G and A264V yielded quantifiable indigo, though only A264G is considered an indigo producer $(\geq 2.5 \mu \mathrm{M})$. Previously reported A264 substitutions to $\mathrm{E}, \mathrm{H}, \mathrm{K}, \mathrm{M}, \mathrm{Q}$, or $\mathrm{C}$ all altered the heme iron ligand sets, inactivating the enzyme. ${ }^{[17 a-c, 25]}$ However, within multiply-substituted variants, A264G contributes to the oxidation of polycyclic aromatic hydrocarbons [26] whereas A264V contributes to the oxidation of a terpene. ${ }^{[27]}$ The two variants of A264 identified here harbour those same conservative substitutions (A264G/V) and constitute, to our knowledge, the first report of point-substituted reactive variants of A264.

Quantification of indigo allowed us to address the longstanding debate of whether the wild-type P450 BM3 (WT) does ${ }^{\text {[7a }}$ ${ }^{28]}$ or does not ${ }^{[11 a, 15 a]}$ hydroxylate indole. Absorption at $620 \mathrm{~nm}$ in bacterial lysates $(n=8)$ was not consistently observed within the linear range of quantification, confirming that WT is, at best, a poor indole oxidizer. Nonetheless, LC-MS unequivocally confirmed production of indigo (Figure S5). The average indigo concentration determined by LC-MS was $1.0 \mu \mathrm{M}$ (Table S2). Indigo formation by WT P450 BM3 is thus detectable but indigo was not consistently produced above the lower limit of the calibration curve $(1.25 \mu \mathrm{M})$.

Our identification of 3 known and 13 unreported variants of P450 BM3 that synthesize indigo demonstrates that there are numerous engineering solutions to produce indigo with this enzyme. Based on this, P450 BM3 may not need tremendous engineering efforts to evolve for oxidation reactions on further non-native substrates. We verified whether the previously reported correlation between oxidation of indole and of other substrates ${ }^{[10 a-c]}$ also applies to the oxidation of 4-phenyl-2butanone (4-PB) to raspberry ketone. P450 BM3 has not been reported to synthesize raspberry ketone nor have any of its variants. GC-MS confirmed the presence of hydroxylated 4-PB at an average concentration of $1.15 \mu \mathrm{M}$, establishing hydroxylated 4-PB formation by WT P450 BM3 near the lower limit of the calibration curve $(1.25 \mu \mathrm{M})$.

We undertook the fluorescence-based NADPH assay with the exogenous substrate 4-PB. We identified 23/31 BM3 variants exhibiting higher NADPH consumption in the presence of 4-PB Hydroxylation of 4-PB was confirmed by GC-MS for $8 / 23$ variants (Table S2; Figure S6). As for indole oxidation, this demonstrates that substrate-specific NADPH consumption overestimates product formation. Among the eight variants with detectable hydroxylated $4-\mathrm{PB}$, four gave concentrations $\geq 2.5 \mu \mathrm{M}(2 \times$ lower limit of the calibration curve) and are qualified as producers (Figure 4; Table S3). Three are variants of position A82 and one of position V78; no indigo-positive variant of positions 87 or 264 hydroxylated 4-PB at significant concentrations, despite variants of position 87 being among the best indigo producers (Figure 3).

These samples have the same mass and retention time as the raspberry ketone standard, consistent with $p$-hydroxylation of the phenyl ring. We confirmed the production of raspberry ketone as the sole oxidation product by preparative $\mathrm{LC}$ and ${ }^{1} \mathrm{H}-\mathrm{NMR}$ with a scaled-up reaction of the most efficient variant, A82Q (Figure S7). Strikingly, $A 82 Q$ and the seven further variants that hydroxylate 4-PB are all indigo producers; we note that variant A82Q has not previously been reported in the context of indigo synthesis. Our results support the initial hypothesis that indigo is a good predictor for raspberry ketone production. We further demonstrate that $A_{b s} 620$ is sufficient to identify promiscuous variants (Figure 4 ).

Although the fluorescence-based NADPH consumption assay overestimated the number of variants of interest, it enclosed a second predictor of promiscuity. Three distinct NADPH consumption patterns were observed: $A$ ) no observable consumption; B) faster consumption in presence then in absence of exogenous substrate; C) very fast consumption both in presence and absence of exogenous substrate (Figure S3). The latter was observed for 9 variants (Figure 4; Table S2). Variants that rapidly consumed NADPH in absence of exogenous substrate could have been thought to exhibit high uncoupling. However, 7/9 fast NADPH consumers were active for indigo formation and $3 / 9$ among those seven were active for raspberry ketone and include the most active variant, A82Q (Figure 4; Table S3). Performing the assay at a lower concentration of NADPH (0.375 mM instead of $1.5 \mathrm{mM}$ ) also successfully identified 6 variants that consume NADPH rapidly in absence of exogenous substrate, where $6 / 6$ were indigo producers and 5/6 were 
raspberry ketone producers (data not shown). Considering that 3 out of 4 of the raspberry ketone producers were identified, this suggests that fast NADPH consumption is a good indicator of activity toward promiscuous substrates.

This work along with previous reports clearly demonstrate that indigo production is a predictor of varied promiscuous reactions. ${ }^{[10 a-c]}$ Here, determination of $A b_{620}$ in bacterial lysate served as a rapid screening tool that is compatible with large libraries. It reduced by $74 \%$ the number of samples to analyze by MS for indigo and raspberry ketone production with only one false positive. If indigo is not a good predictor for a desired reaction, performing the CO-difference assay, the fluorescence-based NADPH assay and MS quantification may be a robust alternative. In our case, this workflow reduced by $45 \%$ and $57 \%$ the number of samples to analyze by MS for indigo and raspberry ketone production, respectively. The fast $\mathrm{NADPH}$-consuming variants reduced the need for MS analysis by $>80 \%$ for both reactions. It identified 7 of the 14 indigo producers and 3 of the 4 raspberry ketone producers, mainly the most active (Tables S2, S3). The workflow provides a universal platform using readily accessible methods for screening non-colorigenic reactions and is amenable to very high-throughput screening.

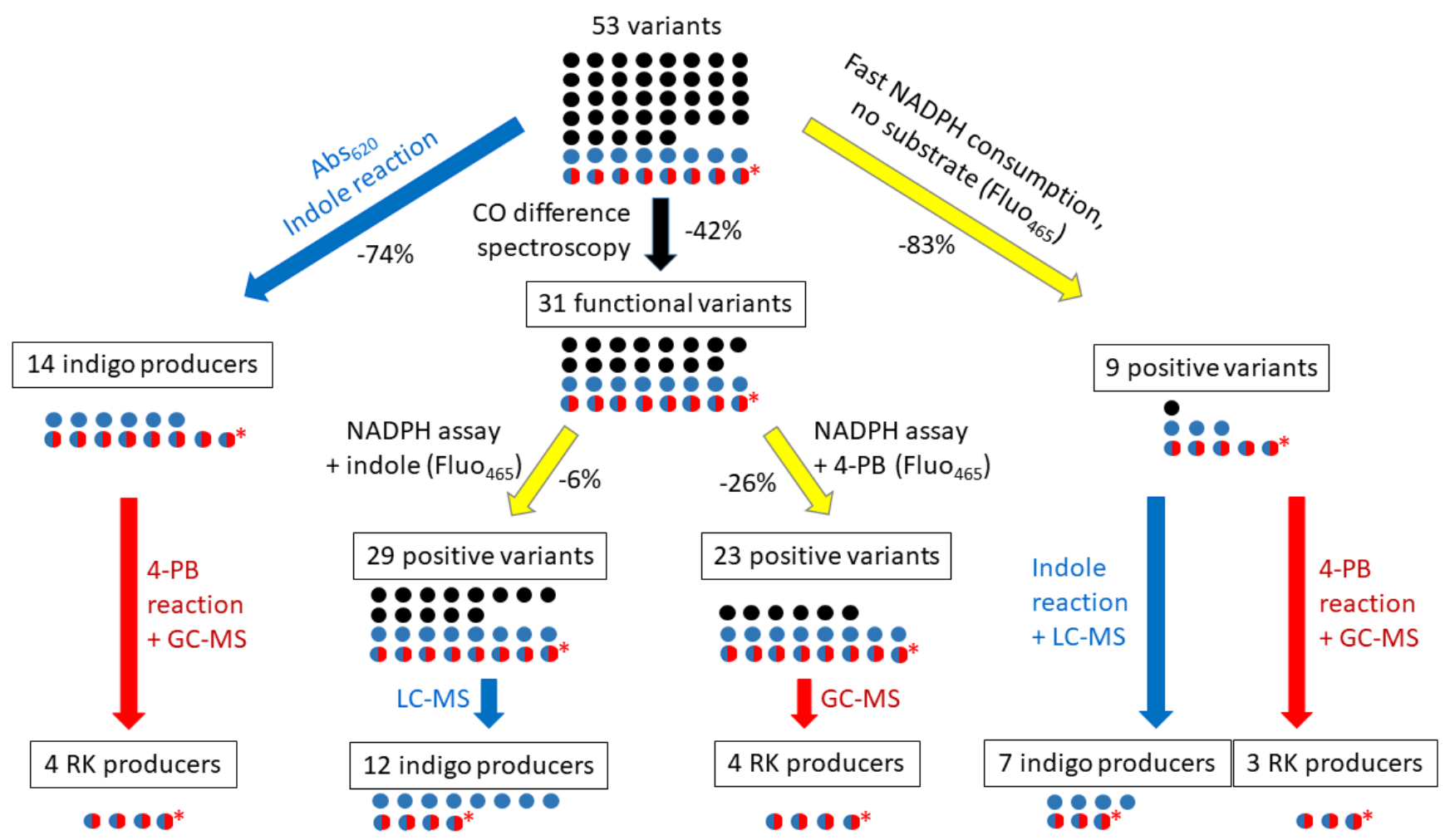

Figure 4. Comparison of workflows to enrich the pool of P450 BM3 variants with indigo or raspberry ketone (RK) producers, defined as giving product $\geq 2 \times$ lowest concentration in the linear portion of the calibration curve. Black, blue and blue/red circles represent negative variants, indigo-only producers and indigo/raspberry ketone producers, respectively. Black, blue, red and yellow arrows represent methods that identify functionally-expressed P450s, indigo production, raspberry ketone production and NADPH consumption, respectively. The fraction of variants eliminated at each step is given beside each arrow as a negative percentage. A red asterisk identifies the top raspberry ketone producer.

Table 2. Initial rates of product formation and coupling efficiency for select P450 BM3 variants. ${ }^{\text {a }}$

\begin{tabular}{|c|cc|cc|}
\hline & \multicolumn{2}{|c|}{$\begin{array}{c}\text { Initial rate } \\
\text { ( } \begin{array}{c}\text { M } / \text { min product formed } \\
\text { per } \mathbf{m g} \text { of enzyme) }\end{array}\end{array}$} & \multicolumn{2}{|c|}{$\begin{array}{c}\text { Coupling efficiency } \\
\mathbf{( \% )}\end{array}$} \\
\cline { 2 - 5 } $\begin{array}{c}\text { P450 } \\
\text { variant }\end{array}$ & Indigo & RK $^{\mathrm{b}}$ & $\begin{array}{c}\text { NADPH to } \\
\text { indigo }\end{array}$ & $\begin{array}{c}\text { NADPH to } \\
\text { RK }\end{array}$ \\
\hline A82F & $1400 \pm 180$ & $35 \pm 1$ & 20 & 0.3 \\
A82W & $580 \pm 54$ & $25 \pm 8$ & 4.8 & 0.1 \\
F87V & $410 \pm 130$ & n.d & 35 & n.d \\
A82Q & $2100 \pm 27$ & $90 \pm 2$ & 84 & 1.8 \\
WT & $8.1 \pm 5$ & n.d & 6.3 & n.d \\
\hline
\end{tabular}

aADPH consumption was measured continuously and product formation was measured discontinuously, under identical conditions. Reaction mixtures contained $5 \mathrm{mM}$ substrate and $250 \mu \mathrm{M} \mathrm{NADPH}$.

${ }^{\mathrm{b}} \mathrm{RK}$ : raspberry ketone.

${ }^{\mathrm{c}}$ n.d.: not detected

We note that the three previously known indigo producers did not include the top raspberry ketone producer, variant $A 82 Q$, demonstrating the importance of considering a broad test-set of indigo-positive variants when searching for promiscuous activity.

Top indigo- or raspberry ketone-producing variants were selected for determination of reactivity and coupling efficiency (Table 2). Initial reaction rates (first 5\%) were determined with 250 $\mu \mathrm{M}$ NADPH to continuously monitor NADPH consumption. These conditions differ from those applied in determination of total indigo formed (Figure 3): NADPH is sub-saturating to prevent saturation of the signal, ${ }^{[7 c]}$ and analysis of initial rates ensures that product inhibition is prevented. Results for variants $\mathrm{A} 82 \mathrm{~F}$ and $\mathrm{A} 82 \mathrm{~W}$ are in the same range as a prior report performed under similar conditions. ${ }^{[7 a]}$ However, variant $\mathrm{A} 82 \mathrm{Q}$ displayed the highest specific activity in indigo synthesis $(2100 \mu \mathrm{M} / \mathrm{min}$ per $\mathrm{mg}$ of $\mathrm{A} 82 \mathrm{Q})$, surpassing even well-known indigo-producing variant A82F (1400 $\mu \mathrm{M} / \mathrm{min}$ per mg of $\mathrm{A} 82 \mathrm{~F}$; Table 2). ${ }^{[23]}$ It also displayed the highest coupling efficiency for this reaction (Table 2).

Interestingly, we observe a clear correlation between the specific activity for indigo and raspberry ketone production calculated from initial rates of reaction calculated for the top producers (Figure 5). This contrasts with the quantification of total product formed using identical volumes of crude lysates, which 
did not display this correlation (Figure 3, Table S3): the four top raspberry ketone producers ranked $1^{\text {st }}, 7^{\text {th }}, 9^{\text {th }}$ and $11^{\text {th }}$ with respect to indigo production, the top raspberry ketone-producing variant $A 82 Q$ ranking $7^{\text {th }}$ for indigo. The characterization of initial reaction kinetics thus improves the capacity of indigo formation to be predictive of a promiscuous activity. Nonetheless, indigo formation is not absolutely predictive of a given promiscuous activity: high indigo-producing variants F87V and F87P do not display significant reactivity with 4-PB. This reinforces the need to broadly screen indigo forming variants for promiscuous reactivity.

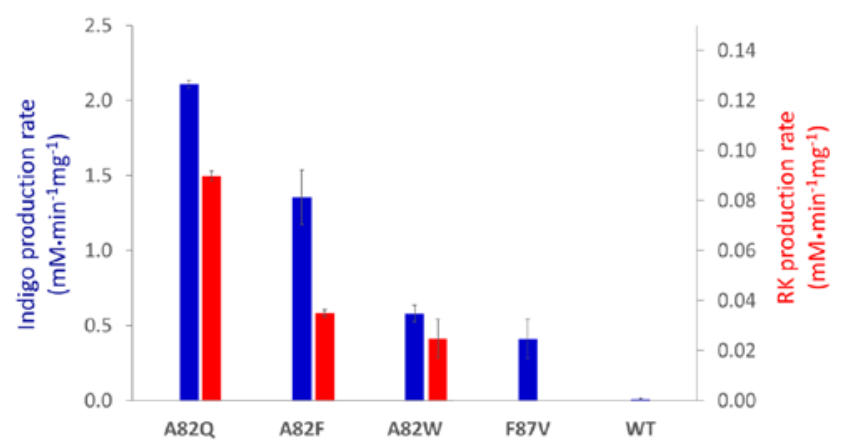

Figure 5. Specific activities of indigo (blue) and raspberry ketone (red) production for select, top indigo- or raspberry ketone-producing variants as per Table 2. Initial rates were determined with discontinuous assays of indigo and raspberry ketone production. Error bars represent the standard deviation on the mean of triplicate measurements.

Variant $\mathrm{A} 82 \mathrm{Q}$ benefits from better productive binding toward 4-PB $\left(\mathrm{K}_{\mathrm{M}}^{\mathrm{app}}=120 \mu \mathrm{M}\right)$ than the second-best variant, $\mathrm{A} 82 \mathrm{~F}\left(\mathrm{~K}_{\mathrm{M}}^{\text {app }}\right.$ $=410 \mu \mathrm{M})$. This is counterbalanced by a 2 -fold lower turnover rate $\left(k_{\mathrm{cat}}^{\text {app }}=14 \mathrm{vs} 30 \mathrm{~s}^{-1}\right)$, resulting in similar catalytic efficiencies (Table 3). The comparatively high productivity of raspberry ketone by variant $A 82 Q$ (Figure 3) appears to result from it displaying both the highest initial rate of NADPH consumption and the greatest coupling efficiency for this reaction (Table 2). Nonetheless, its initial rate $(90 \mu \mathrm{M} / \mathrm{min}$ per $\mathrm{mg}$ of $\mathrm{A} 82 \mathrm{Q})$ and coupling efficiency (1.8\%) in the presence of 4-PB were 24 and 45 -fold lower, respectively, than those in the presence of indole. Although the productivity of raspberry ketone is modest, these results clearly identify variant $\mathrm{A} 82 \mathrm{Q}$ as a candidate for optimization of this promising reaction. It also indicates that variant $A 82 \mathrm{Q}$ should be considered when panning variants of P450 BM3 for promiscuous oxidation reactions.

Table 3. Kinetic parameters of the oxidation of indole and 4-phenyl-2-butanone (4-PB) by P450 BM3 variants A82F and A82Q. ${ }^{2}$

\begin{tabular}{|c|c|c|c|c|}
\hline Substrate: & \multicolumn{2}{|c|}{ Indole } & \multicolumn{2}{|c|}{ 4-PB } \\
\hline P450 BM3 variant: & A82Q & A82F & A82Q & A82F \\
\hline $\mathrm{K}_{M^{a p p}}(\mu \mathrm{M})^{\mathrm{b}}$ & $140 \pm 18$ & $590 \pm 83$ & $120 \pm 23$ & $410 \pm 67$ \\
\hline$k_{\text {cat }^{a p p}}\left(\mathbf{s}^{-1}\right)$ & $6.7 \pm 0.2$ & $17 \pm 0.7$ & $14 \pm 0.4$ & $30 \pm 1$ \\
\hline$k_{\text {cat }} / K_{M^{a p p}}\left(\mu M^{-1} \cdot \mathbf{s}^{-1}\right)$ & 0.05 & 0.03 & 0.1 & 0.07 \\
\hline
\end{tabular}

${ }^{a} \mathrm{NADPH}$ consumption at varying substrate concentrations $(0.125-5 \mathrm{mM}$ fo indole and $0.125-10 \mathrm{mM}$ for 4-PB) and $250 \mu \mathrm{M}$ NADPH. Representative Michaelis-Menten plots are shown in Figure S8.

b app: Kinetic parameters are reported as apparent because NADPH was subsaturating. This allowed determining initial rates by absorbance at $340 \mathrm{~nm}$.

In conclusion, we report 11 previously unknown variants of P450 BM3 that oxidize indole to indigo and we clearly demonstrate the utility of including lower-yielding variants in the search for promiscuous oxidation activity on new substrates. Direct identification of indigo formation by absorbance or identification by the more time-consuming LC-MS gave similar results; culling inactive variants by $\mathrm{CO}$ difference spectroscopy prior to LC-MS was advantageous. By those means, all raspberry ketone-producing variants were identified. A straightforward, alternative route to discovery of promiscuous activity was also discovered: fast NADPH-consuming variants identified many of the most active indigo producers and 3 of the 4 raspberry ketone producers, and most effectively reduced the need for MS analysis.

We have thus engineered variants of P450 BM3 that produce raspberry ketone with a yield in the range of previously reported indigo-producing variants. The breadth of new oxidation reactions that can be accessed on the basis of indigo production is yet unknown; these methods promise to accelerate discovery of new reactivities.

\section{Experimental Section}

Materials

The primers for mutagenesis were obtained from Sigma-Aldrich. Phusion Hot start II polymerase, purification kit, gel extraction kit and miniprep kit were obtained from New England Biolabs. FastDigest restriction enzymes and fast alkaline phosphatase were obtained from Thermo Fisher Scientific. TAKARA ligase was obtained from ClonTech. The cloning vector, pcWORI BM3 WT, was kindly provided by Prof Frances Arnold (Caltech). Indole was obtained from Alfa Aesar. 4-phenyl2-butanone, raspberry ketone and sodium hydrosulfite were obtained from Sigma-Aldrich. FastBreak lysis buffer was obtained from Promega.

PCR were performed with a T100 thermal cycler from Bio-Rad. Cultures were shaken using a Marshall Scientific Labline 4625 titer shaker. Screening was performed with a Beckman Coulter Biomek NXP robot coupled to a DTX880 multimode detector plate reader. LC-MS analysis was performed on a Thermo Scientific Dionex UltiMate 3000 and masses were detected with a Finnigan TSQ Quantum Ultra mass detector. GC-MS analysis was performed with an Agilent $7890 \mathrm{~A}$ and masses were detected with an Agilent 5975C with triple-axis detector. Preparative LC was performed on a Waters apparatus with a SQ Detector 2. Sequencing was operated by the Institute Research of Immunology and Cancerology.

\section{Mutagenesis conditions}

Individual mutagenesis reactions were carried out for each position. A mixture of four primers encoding: NDT, VMA, ATG or TGG at the position of interest was used to perform saturation site-directed mutagenesis at each of 5 position: V78, A82, F87, A264 and T268. Primer sequences are listed in the Supporting Information (Table S1). The megaprimer method of mutagenesis was applied. [29] PCR intermediates were purified before proceeding with further steps. Final PCR products were digested using $\mathrm{BamHI}$ and Sacl according to the manufacturer's instructions. Dpnl was used to eliminate parental DNA. The gel-purified inserts were ligated into the BamHI, Sacl and Fast-AP treated pcWORI BM3 WT vector. Chemically competent E.coli BL21 (DE3) cells were transformed with each ligation and plated on Luria-Bertani (LB) agar with ampicillin $(100 \mu \mathrm{g} / \mathrm{mL})$.

\section{Culture conditions and lysis}

Unless otherwise stated, precultures were grown in $2 \mathrm{~mL}$ deep-well 96-well plates, in $1 \mathrm{~mL} \mathrm{LB}$ with ampicillin $(100 \mu \mathrm{g} / \mathrm{mL})$ for $16 \mathrm{~h}$ at $37^{\circ} \mathrm{C}$, shaking at intensity 5. Expression was carried in the same format, in $1 \mathrm{~mL}$ terrific broth (TB) supplemented with ampicillin $(100 \mu \mathrm{g} / \mathrm{mL}), \quad \delta$ aminolevulinic acid $(12.5 \mu \mathrm{g} / \mathrm{mL})$, thiamine $(5 \mu \mathrm{g} / \mathrm{mL}), 0.125 \mu \mathrm{L}$ trace metals $\left(0.5 \mathrm{~g} \mathrm{MgCl}_{2}, 50 \mathrm{~g} \mathrm{FeCl}_{2} \cdot 6 \mathrm{H}_{2} \mathrm{O}, 1 \mathrm{~g} \mathrm{ZnCl}_{2} \cdot 4 \mathrm{H}_{2} \mathrm{O}, 0.2 \mathrm{~g} \mathrm{CoCl}_{2} \cdot 6 \mathrm{H}_{2} \mathrm{O}\right)$, $1 \mathrm{~g} \mathrm{Na}_{2} \mathrm{MoO}_{4} \cdot 2 \mathrm{H}_{2} \mathrm{O}, 0.5 \mathrm{~g} \mathrm{CaCl}_{2} \cdot 2 \mathrm{H}_{2} \mathrm{O}, 1 \mathrm{~g} \mathrm{CuCl}_{2}, 0.2 \mathrm{~g} \mathrm{H}_{2} \mathrm{BO}_{5}$ in $1 \mathrm{~L} \mathrm{HCl}$ solution $(90 \% \mathrm{v} / \mathrm{v}$ distilled water: concentrated $\mathrm{HCl})$, and $20 \mu \mathrm{L}$ of preculture. The cultures were propagated as above until O.D. reached $0.7-$ 1.0 , induced with $1 \mathrm{mM}$ isopropyl- $\beta-D$-thiogalactoside (IPTG) and further propagated for $20 \mathrm{~h}$ at $22^{\circ} \mathrm{C}$ with shaking. Cultures were pelleted at 1650 $\mathrm{g}, 4^{\circ} \mathrm{C}$ for $20 \mathrm{~min}$ and pellets were frozen for at least $2 \mathrm{~h}$ at $-80^{\circ} \mathrm{C}$ Expression pellets were thawed on ice and resuspended in $400 \mu \mathrm{L}$ lysis buffer (10mM MgSO $4,1 \mathrm{mM}$ DTT, $0.5 \mathrm{mg} / \mathrm{mL}$ lysozyme (Sigma), DNase, $1.5 \mathrm{mM}$ benzamidine hydrochloride hydrate (Fisher), $0.25 \mathrm{mM}$ PMSF (Sigma) in phosphate buffer $0.1 \mathrm{M} \mathrm{pH} 8$ ). Samples were shaken at room temperature for $2 \mathrm{~h}$ at intensity 8 . Lysates were centrifuged at $1643 \mathrm{~g}, 4^{\circ} \mathrm{C}$ for 20 minutes and supernatants were used for further steps.

\section{CO difference spectroscopy}

A CO chamber was built by modifying a standard Pyrex desiccator to include a custom lid with an adjustable gas inlet and outlet. Quantification of the P450 BM3 variants was performed based on a previously described protocol. ${ }^{[8]}$ Lysate $(160 \mu \mathrm{L})$ of each variant was reduced with $40 \mu \mathrm{L}$ of $0.3 \mathrm{M}$ sodium dithionite in $1 \mathrm{M}$ phosphate buffer $\mathrm{pH}$ 8. They were quantified simultaneously in a 96-well plate. A reference measurement was taken at $485 \mathrm{~nm}$. Then, the plate was placed in the CO 
This cycle was repeated twice. A last cycle was performed with CO held for $5 \mathrm{~min}$. The CO difference spectroscopy measurement was immediately taken at $485 \mathrm{~nm}$.

\section{High-throughput absorbance and fluorescence screening assay}

Assays were carried out at room temperature in a 96-well plate format using $7.5 \mu \mathrm{L}$ of bacterial lysate, $5 \mathrm{mM}$ substrate (indole or 4-phenyl2-butanone) in DMSO (2\% final DMSO), $1.5 \mathrm{mM}$ NADPH in a final volume of $140 \mu \mathrm{L}$ with phosphate buffer $0.1 \mathrm{M} \mathrm{pH}$ 8. A reference plate was analyzed under the same conditions, where substrate was replaced with DMSO. Every $30 \mathrm{~min}$, an absorbance measurement was taken at $620 \mathrm{~nm}$ to monitor indigo formation and a fluorescence measurement was taken in parallel (exc $340 \mathrm{~nm}$; em $465 \mathrm{~nm}$ ) to monitor NADPH consumption, for up to $16 \mathrm{~h}$.

\section{Reaction rates and coupling efficiency}

Reactions were performed at $25^{\circ} \mathrm{C}$ in potassium phosphate buffer $0.1 \mathrm{M} \mathrm{pH} 8$ with $250 \mu \mathrm{M}$ NADPH to allow continuous monitoring of initial rates according to NADPH consumption at $340 \mathrm{~nm}$. Initial rates, determined according to the first $5 \%$ of NADPH consumed, were analyzed. Reactions contained $5 \mathrm{mM}$ substrate in DMSO (2\% final DMSO) and between $0.04-0.1 \mu \mathrm{M}$ enzyme, as determined in lysate by $\mathrm{CO}$ difference. Product formation was monitored in a discontinuous fashion using identical reaction conditions. Indigo formation was determined following quenching by addition of 4 parts $\mathrm{CHCl}_{3}$. The spontaneous oxidation of indoxyl to indigo took place overnight. The organic layer was extracted by centrifugation at $3000 \mathrm{~g}$ for $20 \mathrm{~min}$ at $4^{\circ} \mathrm{C}$. Indigo concentration was determined according to absorbance at $620 \mathrm{~nm}$. Raspberry ketone formation was monitored by addition of 2 parts ethyl acetate. Samples were vortexed for $10 \mathrm{~min}$ and centrifuged at $1650 \mathrm{~g}$, at room temperature for $5 \mathrm{~min}$. The organic phase was analyzed by GC-MS.

NADPH to indigo coupling efficiency accounted for two indole oxidation events per molecule of indigo formed:

([indigo formed] $) /(2 \times[$ NADPH consumed] $) \times 100$.

NADPH to RK coupling efficiency:

[RK formed]) / [NADPH consumed] $\times 100$.

\section{Steady-state enzyme kinetics}

All steady-state kinetics were performed at $25^{\circ} \mathrm{C}$ in potassium phosphate buffer $0.1 \mathrm{M} \mathrm{pH} 8$ with $250 \mu \mathrm{M}$ NADPH to allow continuous monitoring of initial rates according to NADPH consumption at $340 \mathrm{~nm}$. Kinetic constants were determined using $0.125-5 \mathrm{mM}$ indole and 0.125 - $10 \mathrm{mM}$ 4-PB in DMSO (2\% final DMSO). Enzyme concentrations were determined in lysate by $\mathrm{CO}$ difference, as above, and were between 0.04 - $0.1 \mu \mathrm{M}$. Initial rates, determined as above, were analyzed.

\section{LC-MS/GC-MS analysis}

The indigo reactions were quenched with $300 \mu \mathrm{L}$ acetonitrile and 15 $\mu \mathrm{L}$ of FastBreak lysis buffer. Raspberry ketone reactions were quenched with $300 \mu \mathrm{L}$ ethyl acetate. All reactions were shaken for $20 \mathrm{~min}$ and centrifuged at $1643 \mathrm{~g}$ at room temperature for $20 \mathrm{~min}$ to remove insoluble matter. Supernatant $(100 \mu \mathrm{L})$ was transferred to a MS vial for analysis.

For LC-MS of indigo, a Phenomenex RP-polar $2 \mathrm{~mm} \times 150 \mathrm{~mm}, 4$ $\mu \mathrm{m}$ column was used at $50^{\circ} \mathrm{C}$ oven temperature. We injected $5 \mu \mathrm{L}$ and applied a gradient of (A) $\mathrm{H}_{2} \mathrm{O} 0.1 \%$ formic acid / (B) ACN $0.1 \%$ formic acid from $40-95 \%$ B over 5 min was applied and held for 3 min, then equilibrated at $60 \%$ A: $40 \%$ B for $2 \mathrm{~min}$. Masses were detected under positive ionization and single-ion monitoring of indole $(118 \mathrm{~m} / \mathrm{z})$, indigo $(263 \mathrm{~m} / \mathrm{z})$ and full scan were taken.

For GC-MS of raspberry ketone, we used an Agilent J\&W 122-7033 DB-WAX $30 \mathrm{~m} \times 250 \mu \mathrm{m}, 0.25 \mu \mathrm{m}$ or a Zebron ZB-WAXplus $30 \mathrm{~m} \times 250$ $\mu \mathrm{m}, 0.25 \mu \mathrm{m}$ column. In the DB-WAX, we injected $1 \mu \mathrm{L}$ with an inlet temperature of $270^{\circ} \mathrm{C}$, pressure of 11.8 psi and a flow of $1.2 \mathrm{~mL} / \mathrm{min}$. A temperature gradient from $80^{\circ} \mathrm{C}$ to $240^{\circ} \mathrm{C}$ in $8.89 \mathrm{~min}$ was applied and held at $240^{\circ} \mathrm{C}$ for $16 \mathrm{~min}$. In the ZB-WAXplus, we injected $1 \mu \mathrm{L}$ with an inlet temperature of $280^{\circ} \mathrm{C}$, pressure of $11.8 \mathrm{psi}$ and a flow of $1 \mathrm{~mL} / \mathrm{min}$. A temperature gradient from $190^{\circ} \mathrm{C}$ to $240^{\circ} \mathrm{C}$ in $2.28 \mathrm{~min}$ was applied and held at $240^{\circ} \mathrm{C}$ for $10 \mathrm{~min}$. Masses were detected under positive ionization and single-ion monitoring of the internal standard t-butyl-phenol $(135 \mathrm{~m} / \mathrm{z})$, 4-phenyl-2-butanone $(121 \mathrm{~m} / \mathrm{z})$ and the fragment of raspberry ketone (107 $m / z)$.

\section{NMR identification of raspberry ketone}

The 4-phenyl-2-butanone oxydation reaction was scaled-up in a 300 $\mathrm{mL}$ Erlenmeyer using $2.5 \mathrm{~mL}$ of lysate from variant $\mathrm{A} 82 \mathrm{O}, 1 \mathrm{~mL}$ of $250 \mathrm{mM}$ 4-phenyl-2-butanone, $5 \mathrm{~mL}$ of $15 \mathrm{mM} \mathrm{NADPH}$ and $41.5 \mathrm{~mL}$ of $0.1 \mathrm{M}$ potassium phosphate buffer $\mathrm{pH} 8$ in a total volume of $50 \mathrm{~mL}$. The reaction was performed for 16 hours at $25^{\circ} \mathrm{C}$ with shaking at $250 \mathrm{rpm}$. The product was extracted with $100 \mathrm{~mL}$ of ethyl acetate and evaporated at $40^{\circ} \mathrm{C}$ on a rotary evaporator and taken up in $1 \mathrm{~mL}$ of ethyl acetate for analysis.
Isolation of the hydroxylated product(s) was done by preparative LC with a Phenomenex RP-polar $19 \mathrm{~mm} \times 150 \mathrm{~mm}, 4 \mu \mathrm{m}$ column. We injected $8 \times 100 \mu \mathrm{L}$ of the sample. An initial gradient of (A) $\mathrm{H}_{2} \mathrm{O} 0.1 \%$ formic acid / (B) $\mathrm{MeOH} 0.1 \%$ formic acid from $85-33 \% \mathrm{~B}$ in 13.5 min was applied and held at $10 \%$ A: $90 \%$ B for 1 min, then equilibrated at $15 \%$ A: $85 \%$ B for 5 $\min$. We monitored the mass of the raspberry ketone fragment as a sodium adduct $(107.1+22 \mathrm{~m} / \mathrm{z})$. Fractions containing the correct mass and retention time were collected, combined and evaporated for NMR analysis. ${ }^{1} \mathrm{H} \mathrm{NMR}\left(700 \mathrm{MHz}, \mathrm{CDCl}_{3}, 25^{\circ} \mathrm{C}, \mathrm{TMS}\right): \delta=7.06(\mathrm{~m}, 2 \mathrm{H}), \delta=6.76(\mathrm{~m}, 2 \mathrm{H})$ $\delta=2.83(\mathrm{t}, J=7.5 \mathrm{~Hz}, 2 \mathrm{H}), \delta=2.72(\mathrm{t}, J=7.5,2 \mathrm{H}), \delta=2.16(\mathrm{~s}, 3 \mathrm{H}) \mathrm{ppm}$.

\section{Acknowledgements}

All authors belong to the Québec Network for Protein Function, Engineering and Applications (PROTEO) and the Center of Green Chemistry and Catalysis (CGCC). We thank Marie-Christine Tang, Louiza Mahrouche and Dr. Alexandra Furtos from the Centre régional de spectrométrie de masse at Université de Montréal for their invaluable help; the Université of Montréal Chemistry workshop for $\mathrm{CO}$ chamber design and technical assistance; Prof. Frances Arnold for providing the P450 BM3 gene; and Jacynthe L. Toulouse, Vanessa Kairouz, Cedric Malveau and Dr. Pedro Alguiar for helpful discussions and suggestions. This work was funded by Natural Sciences and Engineering Council (NSERC) grant 227853 and the Fonds Québecois de la Recherche sur la Nature et les Technologies (FQRNT) grant 181877. O.R. and M.C.J.C.C. held PROTEO scholarships, M.C.J.C.C. and J.N.B. were recipients NSERC scholarships, M.C.J.C.C. held a scholarship from the U. de Montréal, J.N.B. held an FQRNT scholarship, A.F. and A.H.-P. held NSERC CREATE scholarships and S.I. held a scholarship from CGCC.

\section{Conflict of interest}

\section{The authors declare no conflict of interest.}

Keywords: Biocatalysis, enzyme engineering, high-throughput screening, indigo, raspberry ketone

\section{References}

[1] a) D. Lin, M. Xiao, J. Zhao, Z. Li, B. Xing, X. Li, M. Kong, L. Li, O Zhang, Y. Liu, H. Chen, W. Qin, H. Wu, S. Chen, Molecules 2016, 21, 1374-1393; b) C. Caleja, A. Ribeiro, M. F. Barreiro, I. C. F. R. Ferreira, Curr. Pharm. Des. 2017, 23, 2787-2806.

[2] a) Y. C. Tsai, B. C. Yang, W. H. Peng, Y. M. Lee, M. H. Yen, P. Y. Cheng, Phytomedicine 2017, 31, 11-17; b) V. Khan, S. Sharma, U. Bhandari, S. M. Ali, S. E. Haque, Life Sci. 2018, 194, 205-212; c) K. S. Park, Planta Med. 2010, 76, 1654-1658; d) C. Ulbricht, M. Catapang, J. Conquer, D. Costa, S. Culwell, D. D'Auria, R. Isaac, C. Le, E. Marini, A. Miller, M. Mintzer, M. Nguyen, K. Salesses, Alternative and Complementary Therapies \$V 19 2013, 19, 98-100.

[3] a) J. Beekwilder, I. M. van der Meer, O. Sibbesen, M. Broekgaarden, I. Qvist, J. D. Mikkelsen, R. D. Hall, Biotechnol. J. 2007, 2, 1270-1279; b) L. R. Smith, The Chemical Educator 1996, 1, 1-18; c) D. Lee, N. D. Lloyd, I. S. Pretorius, A. R. Borneman, Microb. Cell Fact. 2016, 15, 49; d) W. F. Hoelderich, V. Ritzerfeld, Appl. Catal., A 2015, 504, 654-663; e) B. Kosjek, W. Stampfer, R. v. Deursen, K. Faber, W. Kroutil, Tetrahedron 2003, 59, 9517-9521.

[4] a) F. Hannemann, A. Bichet, K. M. Ewen, R. Bernhardt, Biochim. Biophys. Acta, Gen. Subj. 2007, 1770, 330-344; b) P. R. Ortiz de Montellano, Cytochrome P450 : structure, mechanism, and biochemistry, Springer, 2015.

[5] P. Anzenbacher, E. Anzenbacherova, Cell. Mol. Life Sci. 2001, 58, 737-747.

[6] a) V. B. Urlacher, M. Girhard, Trends Biotechnol. 2012, 30, 26-36; b) S. Schulz, M. Girhard, V. B. Urlacher, ChemCatChem 2012, 4, 1889-1895; c) E. T. Farinas, M. Alcalde, F. H. Arnold, Tetrahedron 2004, 60, 525-528.

[7] a) W. C. Huang, A. C. G. Westlake, J. D. M. M. Gordon Joyce, P. C. E. Moody, G. C. K. Roberts, J. Mol. Biol. 2007, 373, 633-651; b) R. T. Ruettinger, L. P. Wen, A. J. Fulco, J. Biol. Chem. 1989, 264, 10987-10995; c) C. J. C. Whitehouse, S. G. Bell, L. L. Wong, Chem. Soc. Rev. 2012, 41, 1218-1260; d) C. J. C. Whitehouse, S. G. Bell, H. G. Tufton, R. J. P. Kenny, 
L. C. I. Ogilvie, L.-L. Wong, Chem. Commun. 2008, 966-968; e) F. E. Zilly J. P. Acevedo, W. Augustyniak, A. Deege, U. W. Häusig, M. T. Reetz Angew. Chem. Int. Ed. 2011, 50, 2720-2724.

[8] a) F. H. Arnold, G. Georgiou, Directed Enzyme Evolution: Screening and Selection Methods, Humana Press, Totowa, 2003; b) J. B. Behrendorff, W. Huang, E. M. Gillam, Biochem. J. 2015, 467, 1-15.

[9] a) A. S. Norul, M. Nazira, S. N. Tajuddin, Aust. J. Basic Appl. Sci. 2015, 9 155-159; b) A. Bahan, M. Gaharu, B. Tinggi, D. Cara, N. Ismail, M. Ali, N. A. Mohamad Ali, M. Jamil, M. Hezri, M. H. Fazalul Rahiman, S. N. Tajuddin, M. N. Taib, Malaysian J. Anal. Sci. 2013, 17, 403-413.

[10] a) P. P. Kelly, A. Eichler, S. Herter, D. C. Kranz, N. J. Turner, S. L. Flitsch Beilstein J. Org. Chem. 2015, 11, 1713-1720; b) A. Celik, R. E. Speight, N. J. Turner, Chem. Commun. 2005, 3652-3654; c) S. H. Park, D. H. Kim, D. Kim, D. H. Kim, H. C. Jung, J. G. Pan, T. Ahn, D. Kim, C. H. Yun, Drug Metab. Dispos. 2010, 38, 732-739; d) Q. S. Li, J. Ogawa, R. D. Schmid, S Shimizu, Appl. Environ. Microbiol. 2001, 67, 5735-5739; e) W. T. Sulistyaningdyah, J. Ogawa, Q.-S. Li, R. Shinkyo, T. Sakaki, K. Inouye, R. D. Schmid, S. Shimizu, Biotechnol. Lett. 2004, 26, 1857-1860; f) M. Budde M. Morr, R. D. Schmid, V. B. Urlacher, ChemBioChem 2006, 7, 789-794

[11] a) O. S. Li, U. Schwaneberg, P. Fischer, R. D. Schmid, Chemistry (Easton) 2000, 6, 1531-1536; b) L.-D. Syntrivanis, L. L. Wong, J. Robertson Eur. J. Org. Chem. 2018, 2018, 6369-6378; c) Y. Li, L. L. Wong, Angew. Chem. Int. Ed. Engl. 2019, 58, 9551-9555; d) K. Kühnel, S. C. Maurer, Y Galeyeva, W. Frey, S. Laschat, V. B. Urlacher, Adv. Synth. Catal. 2007, 349, 1451-1461.

[12] a) J. C. Splitstoser, T. D. Dillehay, J. Wouters, A. Claro, Sci. Adv. 2016, 2, 1-4; b) B. D. Ensley, B. J. Ratzkin, T. D. Osslund, M. J. Simon, L. P. Wackett, D. T. Gibson, Science 1983, 222, 167-169; c) C. S. W. Koehler, Today's Chemist at Work 1999, 8, 85-91.

[13] a) L. Cheng, S. Yin, M. Chen, B. Sun, S. Hao, C. Wang, Curr. Microbiol. 2016, 73, 248-254; b) E. M. Gillam, A. M. Aguinaldo, L. M. Notley, D. Kim, R. G. Mundkowski, A. A. Volkov, F. H. Arnold, P. Soucek, J. J. DeVoss, F. P. Guengerich, Biochem. Biophys. Res. Commun. 1999, 265, 469-472.

[14] a) A. M. Sawayama, M. M. Y. Chen, P. Kulanthaivel, M.-S. Kuo, H. Hemmerle, F. H. Arnold, Chemistry (Easton) 2009, 15, 11723-11729; b) E. Vottero, V. Rea, J. Lastdrager, M. Honing, N. P. E. Vermeulen, J. N. M. Commandeur, J. Biol. Inorg. Chem. 2011, 16, 899-912.

[15] a) H. M. Li, L. H. Mei, V. B. Urlacher, R. D. Schmid, Appl. Biochem. Biotechnol. 2008, 144, 27-36; b) Z. Pengpai, H. Sheng, M. Lehe, L. Yinlin J. Zhihua, H. Guixiang, Appl. Biochem. Biotechnol. 2013, 171, 93-103.

[16] a) M. M. Y. Chen, C. D. Snow, C. L. Vizcarra, S. L. Mayo, F. H. Arnold Protein Eng., Des. Sel. 2012, 25, 171-178; b) M. W. Peters, P. Meinhold, A Glieder, F. H. Arnold, J. Am. Chem. Soc. 2003, 125, 13442-13450.

[17] a) H. M. Girvan, H. E. Seward, H. S. Toogood, M. R. Cheesman, D. Leys, A. W. Munro, J. Biol. Chem. 2007, 282, 564-572; b) H. M. Girvan, K. R. Marshall, R. J. Lawson, D. Leys, M. G. Joyce, J. Clarkson, W. E. Smith, M. R. Cheesman, A. W. Munro, J. Biol. Chem. 2004, 279, 23274-23286; c) H M. Girvan, H. S. Toogood, R. E. Littleford, H. E. Seward, W. E. Smith, I. S. Ekanem, D. Leys, M. R. Cheesman, A. W. Munro, Biochem. J. 2009, 417 65-76; d) P. S. Coelho, E. M. Brustad, A. Kannan, F. H. Arnold, Science 2013, 339, 307-310; e) K. D. Dubey, B. Wang, M. Vajpai, S. Shaik, Chem. Sci. 2017, 8, 5335-5344.

[18] L. X. Tang, H. Gao, X. C. Zhu, X. Wang, M. Zhou, R. X. Jiang, BioTechniques 2012, 52, 149-+

[19] E. M. Gillam, L. M. Notley, H. Cai, J. J. De Voss, F. P. Guengerich Biochemistry 2000, 39, 13817-13824.

[20] G. E. Tsotsou, A. E. G. Cass, G. Gilardi, Biosens. Bioelectron. 2002, 17 119-131.

[21] a) P. J. Loida, S. G. Sligar, Biochemistry 1993, 32, 11530-11538; b) D. Holtmann, F. Hollmann, ChemBioChem 2016, 17, 1391-1398; c) S Kadkhodayan, E. D. Coulter, D. M. Maryniak, T. A. Bryson, J. H. Dawson, J. Biol. Chem. 1995, 270, 28042-28048; d) C. J. Whitehouse, W. Yang, J. A Yorke, B. C. Rowlatt, A. J. Strong, C. F. Blanford, S. G. Bell, M. Bartlam, L. L. Wong, Z. Rao, ChemBioChem 2010, 11, 2549-2556.

[22] M. J. Cryle, J. J. D. Voss, ChemBioChem 2008, 9, 261-266

[23] W. C. Huang, A. C. Westlake, J. D. Marechal, M. G. Joyce, P. C. Moody, G. C. Roberts, J. Mol. Biol. 2007, 373, 633-651.

[24] M. Dietrich, T. A. Do, R. D. Schmid, J. Pleiss, V. B. Urlacher, J. Biotechnol. 2009, 139, 115-117.

[25] M. G. Joyce, H. M. Girvan, A. W. Munro, D. Leys, J. Biol. Chem. 2004, 279, 23287-23293.

[26] A. B. Carmichael, L. L. Wong, Eur. J. Biochem. 2001, 268, 3117-3125.

[27] A. Seifert, M. Antonovici, B. Hauer, J. Pleiss, ChemBioChem 2011, 12 , 1346-1351.

[28] a) Q.-S. Li, J. Ogawa, R. D. Schmid, S. Shimizu, Biosci., Biotechnol., Biochem. 2005, 69, 293-300; b) Y. Lu, L. Mei, J. Ind. Microbiol. Biotechnol. 2007, 34, 247-253.

[29] J. Sanchis, L. Fernandez, J. D. Carballeira, J. Drone, Y. Gumulya, H. Hobenreich, D. Kahakeaw, S. Kille, R. Lohmer, J. J. Peyralans, J. Podtetenieff, S. Prasad, P. Soni, A. Taglieber, S. Wu, F. E. Zilly, M. T. Reetz, Appl. Microbiol. Biotechnol. 2008, 81, 387-397. 


\section{FULL PAPER}

A leap from jeans to raspberries

We accelerate the identification of indigo-producing variants of P450 $\mathrm{BM} 3$. This facilitates the discovery of promiscuous oxidation reactions such as synthesis of the high value product, raspberry ketone.

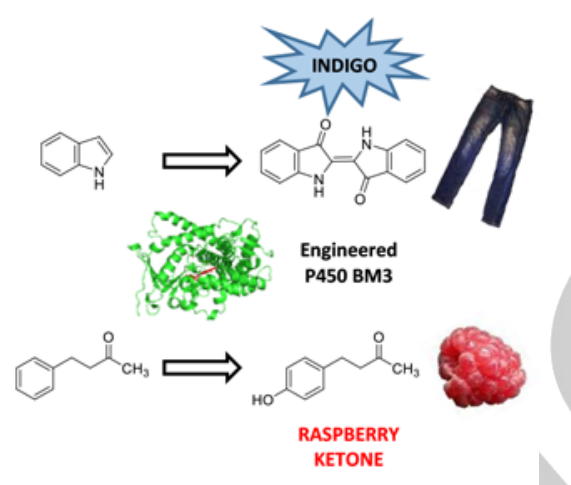

Olivier Rousseau, Maximilian C.J.C.C Ebert, Daniela Quaglia, Ali Fendri, Adem H.-Parisien, Jonathan N. Besna, Saathanan lyathurai, Joelle $N$.

Pelletier*

Page No. - Page No.

Indigo formation and rapid NADPH consumption provide robust prediction of raspberry ketone synthesis by engineered cytochrome P450 BM3. 